\title{
A compreensão sobre socialização e criança na educação infantil: o que muda com o curso de pedagogia?
}

Adir Luiz Ferreira

Maria Patrícia Costa de Oliveira

Universidade Federal do Rio Grande do Norte

\section{Resumo}

Na formação da pedagogia para a El-Educação Infantil encontram-se as noções de criança, infância e socialização, temas destacados pela sociologia da infância. Partindo da experiência de estágio dos estudantes que atuaram na El, identificar-se-ia a compreensão crítica dessas noções? Assim, realizou-se uma pesquisa com as falas dos estudantes de pedagogia da Universidade Federal do Rio Grande do Norte, analisando as concepções de criança e de infância, antes e após entrarem no curso; a importância da El na formação da criança; a percepção da socialização das crianças; o papel da escola no processo de socialização; e, o olhar da professora diante da atuação infantil na rotina escolar. Como resultado, dificuldades foram reveladas na formação dos professores de El, devido às carências pedagógicas nos fundamentos sobre infância e socialização. Porém, mesmo tardiamente, o curso provocou mudanças nos estudantes, reconhecendo-se a importância da socialização e da atuação das crianças na escola.

Palavras-chave: Formação docente. Curso de pedagogia. Educação Infantil e infância. Socialização escolar. Sociologia da infância.

\section{The comprehension about socialization and children in the Child Education: what changes with the course of pedagogy?}

\begin{abstract}
In the pedagogy formation for the CE-Child Education, it found the notions of child, childhood, and socialization, themes highlighted by the childhood sociology. From the practical experience of the Pedagogy's students had acting in the CE, it identifies a critical comprehension of these notions? Thus, it realized a research with the speeches of the Pedagogy's students of UFRN to understand following aspects: the conceptions of child and childhood before and after entering course; the importance of CE to the children formation; the perception of children's socialization; the role of the school on child socialization; and, the teacher gaze before the children acting in the school routine. In conclusion, some issues are revealed in teachers' formation to the CE, because of the pedagogical lacks on fundaments about childhood and socialization. However, even tardily, the course provokes changes in the students, with a renew recognition about the importance of the school socialization of child.
\end{abstract}


A compreensão sobre socialização e criança na educação infantil: o que muda com o curso de pedagogia?

Keywords: Teachers formation. Pedagogy course. Child Education and childhood. School socialization. Childhood sociology.

\section{La comprensión sobre socialización y niño en la educación infantil: ¿lo que cambia con el curso de pedagogía?}

\section{Resumen}

En la formación de la pedagogía hacia la El-Educación Infantil se encuentran las nociones de niño, infancia y socialización, temas destacados por la sociología de la infancia. ¿Partiéndose de la experiencia práctica de los estudiantes de pedagogía para actuaren en la El se identificaría la comprensión critica de estas nociones? Así, se ha realizado una pesquisa con las falas de los estudiantes de la Universidade Federal do Rio Grande do Norte para comprehender las concepciones y visiones del niño e de la infancia antes y después entraren en el curso; la importancia de la El hacia la formación del niño; la percepción de la socialización de los niños; el papel de la escuela en el proceso de socialización; y la mirada de la maestra delante de la actuación del niño en la rutina escolar. Como resultado, fueran reveladas dificultades en la formación de docente por la El, debido a las carencias pedagógicas en los fundamentos sobre infancia y socialización. Sin embargo, mismo tardíamente, el curso a provocado cambios en los estudiantes, se reconociendo la importancia de la socialización en la actuación de los niños en la escuela.

Palabras clave: Formación docente. Curso de pedagogía. Educación Infantil e infancia. Socialización escolar. Sociología de la educación.

\section{Introdução}

Em paralelo às leituras, formações e transformações conceituais vivenciadas pelos estudantes de pedagogia no decorrer do curso, adquire-se nesse percurso uma vasta bagagem de conhecimentos acadêmicos e profissionais que configuram a formação no ensino superior em pedagogia. Entre os fundamentos que contribuem decisivamente nas orientações pedagógicas práticas dos futuros educadores, se encontram os temas educacionais e sociológicos voltados para a El-Educação Infantil, os quais se espera que estejam incluídos nas abordagens pedagógicas das escolas e na organização didática do ensino. Nessa formação e nas transformações vivenciadas pelos estudantes de pedagogia, encontram-se os conhecidos fundamentos sociais e psicológicos que orientam práticas pedagógicas na El-Educação Infantil, incluindo as noções de criança, infância e socialização, que são temas básicos destacados 
nos estudos da sociologia da infância. Então, a questão de fundo é saber se na formação prática dos estudantes de pedagogia para atuarem na El poderíamos identificar a compreensão crítica desses conhecimentos fundamentais.

As mudanças envolvidas nesse processo de formação do professor da El, segundo as diretrizes curriculares definidas para o curso de pedagogia nessa área (BRASIL, 2010), seriam entendidas com mais profundidade com uma análise das concepções ou visões dos estudantes com referência às noções escolares de criança, infância e socialização. Buscando essa compreensão, poderiam ser comparadas noções como concepção de criança antes e após entrar no curso de pedagogia; importância da Educação Infantil para a formação da criança; percepção da socialização das crianças na El; papel da professora e da escola no processo de socialização; e, o olhar da professora diante da atuação da criança nas atividades e na própria organização da rotina escolar.

\section{Os sujeitos e o lugar da pesquisa: os estudantes de pedagogia diante da educação infantil}

Nessa ótica, adotamos as noções de criança, infância e socialização, como objetivo de análise para uma pesquisa qualitativa, que em seu momento empírico fez uso de entrevistas semiestruturadas com os estudantes do curso de pedagogia. Com essa orientação sobre o tema de estudo, tivemos como suporte empírico para essa categorização interpretativa as contribuições originadas de entrevistas presenciais semiestruturadas, realizadas no primeiro semestre de 2016, com nove estudantes veteranos, avançados na experiência acadêmica do currículo do curso presencial de pedagogia da Universidade Federal do Rio Grande do Norte (UFRN), matriculados no $5^{\circ}$ e no $6^{\circ}$ semestre. A partir de suas falas, chegou-se a sucessivas organizações e seleções dos dados, expressos através de tabulações, categorizações e interpretações dos resultados das entrevistas.

Sobre a metodologia utilizada nesse estudo, nos valemos das orientações gerais de diferentes abordagens do método qualitativo que possam ser aplicadas à pesquisa científica em educação. Especificamente sobre as nossas entrevistas, consideramos essa abordagem de aproximação dos sujeitos tanto como técnica de coleta de dados quanto momento de produção do discurso 
A compreensão sobre socialização e criança na educação infantil: o que muda com o curso de pedagogia?

(ROSA; ARNOLDI, 2006). Nos procedimentos metodológicos foram observados igualmente critérios científicos da prática de entrevistas na pesquisa educacional, como consentimento informado, anonimato na divulgação, cenário confortável, estímulo à conversação e para se ampliar entendimentos, cuidado com as transcrições, etc. (POWNEY; WATTS, 1987).

A gravação dos relatos desses estudantes nos permitiu, ao final, compilar um extenso conjunto de informações sobre os entendimentos associados à sua formação. Ainda que possamos identificar nessa formação diferentes níveis de interesse temático, domínio teórico e profundidade sobre as noções de criança, infância e educação infantil, é plausível considerar suas falas como sendo representativas de conhecimentos desenvolvidos a partir da experiência acadêmica em cursos, seminários, discussões, estágios, entre outras atividades formativas. Como procedimento metodológico de base para a codificação dos dados qualitativos nos inspiramos na teoria fundamentada, visando "[...] gerar de forma intuitiva ideias teóricas novas ou hipóteses a partir dos dados, em vez de testar teorias especificadas de antemão" (GIBBS, 2009, p. 71).

Com essa perspectiva, a codificação das falas dividiu-se em três momentos sucessivos: uma codificação aberta, uma codificação axial e uma 272 codificação seletiva. No primeiro momento, procedemos a sucessivas leituras reflexivas dos textos, para se incorporar e detectar as categorias relevantes, isto é, os elementos reveladores das concepções dos estudantes. No segundo momento, refinamos e relacionamos as categorias identificadas, com a escolha de trechos e fragmentos significativos das falas, subjacentes aos vários termos utilizados pelos estudantes entrevistados. No terceiro momento, selecionamos as categorias fundamentais ou centrais, organizadas como blocos semânticos lógicos (sintéticos) para uma análise de conteúdo, que fizeram com que as outras categorias se conectassem como uma história ou relato identificável relacionado com o objetivo de análise desse trabalho. Dessa forma, justificam-se as bases para a definição de categorias e consequentemente para as interpretações dos seus entendimentos sobre: infância, criança, socialização escolar na Educação Infantil e atuação observada das professoras com as crianças.

$\bigcirc$ critério específico para a escolha dos nove sujeitos entrevistados, foi o de que eles estivessem cursando ou já tivessem cursado a disciplina do Estágio Supervisionado na Educação Infantil. Quanto ao gênero dos sujeitos entrevistados, um deles era do sexo masculino e os outros oito do sexo feminino. Quanto à faixa etária, as idades variaram de 20 anos até 50 anos. $\bigcirc$ 
principal critério de escolha foi o de estarem vinculados às atividades curriculares de estágio relacionadas com a educação infantil, atuando ou já tendo atuado nos estabelecimentos escolares. Assim, no momento das entrevistas, direta ou indiretamente, eles puderam relacionar nos seus relatos a sua formação teórica com as práticas desenvolvidas na Educação Infantil durante o período de estágio nas escolas. Além desse estágio ter como pré-requisito as disciplinas de fundamentos, entre as quais está a de sociologia da educação, justamente é nesse o componente curricular que se proporciona aos estudantes de pedagogia um intenso contato com as crianças em ambiente escolar, no qual as crianças vivenciam cotidianamente a experiência da socialização. Supôs-se, então, que esses estudantes seriam aqueles que já tivessem assimilado tanto as discussões das disciplinas de fundamentos da educação, como história, sociologia e psicologia, quanto os componentes mais especificamente pedagógicos e didáticos, os quais potencialmente se integrariam como importantes contribuições, teóricas e práticas, para um melhor esclarecimento e atuação na educação infantil.

Com a realização dessas entrevistas, feitas em encontros únicos, com a gravação digital e posterior transcrição, obtivemos um material rico a partir do qual foi possível depreender inferências que se aproximam de muitos dos argumentos usados internacionalmente pelos sociólogos da infância em suas discussões sobre a visão sociológica da infância e da criança na sociedade atual e na educação infantil (CORSARO, 2011 ; PINTO, 1997; QVORTRUP, 2010; SARMENTO, 2013; SIROTA, 20011. Essa também é a perspectiva de pesquisadores no Brasil, quando destacam a dimensão social fundamental na escola da Educação Infantil que deve ser levada em conta na proposta pedagógica e no currículo, assim como na prática cotidiana de educadores com crianças (MARCHI, 2010; LEVINDO, 2015; SIQUEIRA, 2013).

Mas, no caso da educação, essas perspectivas geralmente não se reduziriam apenas a objetivos em uma pesquisa abstrata e teórica, mas também se buscando igualmente mudanças nas práticas educacionais em suas dimensões pedagógicas e sociológicas. Por isso, pretendemos ter feito do momento da entrevista uma forma para se abordar, registrar e analisar as ideias e motivações dos sujeitos sobre sua compreensão e saberes difundidos no cotidiano escolar, local em que ocorre o fenômeno da socialização na Educação Infantil. Essa fenomenologia social vincula-se às abordagens de uma sociologia interacionista, que também pode ser esclarecedora para os estudos sociológicos 
A compreensão sobre socialização e criança na educação infantil: o que muda com o curso de pedagogia?

no contexto escolar, pois essa perspectiva pressupõe a vida social como uma composição compartilhada. Contudo, dessa experiência coletiva também se pode depreender que haveriam potenciais conflitos de interpretações:

A vida social é, portanto, o produto de uma "composição" entre cada um e os outros, de uma parceria e de um acerto de contas. Produto constantemente ameaçado, contestado resultado e efeito de uma "negociação contínua" entre os atores portadores de interpretações e de "definições de situações" divergentes (PLAISANCE, 1997, p. 1431.

Dessa forma, é lógico imaginar que no sentido das práticas escolares voltadas para a infância, essas interpretações sejam construídas no decorrer da formação docente. E é justamente nas experiências de estágio na Educação Infantil que as definições dos atores sociais lestudantes estagiários, professores regentes e crianças) se confrontariam, resultando em mudanças de visão e compreensões. Assim, é partir dessas referências, da sociologia da infância especificamente e da sociologia em geral, que pudemos começar a analisar as possibilidades críticas dessas perspectivas que tratam das relações entre 274 criança-infância-escola. E seriam essas as contribuições que fundamentariam o processo de formação dos professores que irão atuar diretamente com as crianças, ajudando-os a terem uma nova compreensão sobre a importância e os significados educativos atribuídos à socialização infantil e escolar.

\section{Concepções e visões de criança e infância: a importância da educação infantil}

P planejamento configura, pois, um processo multidimensional e pode servir como tática de poder ora para manter uma determinada posição, ora para gerar a mudança social. A apresentação e interpretação dos dados se baseou nos resultados dessas entrevistas semiestruturadas com os estudantes do curso de pedagogia, investigando-se especialmente suas concepções e visões sobre essa criança-infância-escola. Os sujeitos entrevistados, nos tópicos perguntados, responderam com várias ideias ou expressões. Assim, a quantidade de respostas, apresentadas como ideias distinguíveis ou expressões-chaves discerníveis, variaram para cada tópico, sem correspondência com o número dos entrevistados. Os trechos, ou fragmentos de textos (eventualmente com a escrita 
reconstruída), devem ser vistos como recortes e seleções representativas, tendo sido considerados como expressões de ideias e formulações de linguagens, mostrando os conteúdos implícitos e os entendimentos tácitos dos entrevistados. Denotam, dessa forma, indícios significantes das concepções inconscientes do pensamento e da prática em educação relacionadas à infância, à criança e à educação infantil. São concepções, tomadas em geral, na sociedade, ou em particular, no ambiente escolar, as quais provavelmente os influenciaram nas suas experiências de formação no curso de pedagogia.

Nessa ótica, após a análise e interpretação da parte das entrevistas, organizadas em questões desencadeadoras, buscamos relacionar as primeiras impressões ou representações preliminares dos estudantes de pedagogia sobre as concepções centrais desse estudo: criança, infância e educação infantil. Com as expressões apresentadas pelos próprios estudantes entrevistados, pensamos que foi possível identificar e compreender suas concepções e suas visões, como expressões distintas, porém articuladas, na mente e na prática dos sujeitos da pesquisa. Para os fins desse estudo, esclarecemos que se adotou uma diferença semântica, evidentemente com efeitos sobre à análise, entre concepção e visão, com a primeira significando o conteúdo cognitivo subjacente, profissional e valorativo (com elementos inconscientes) para o entendimento da realidade; enquanto a segunda seria a expressão manifestada na linguagem como opinião declarada sobre a atuação de si ou do outro nessa mesma realidade. No sentido temporal e sincrônico, ou seja, no percurso acadêmico e formativo dos estudantes de pedagogia, os conhecimentos sobre criança, infância e educação infantil foram relatadas como categorizações dinâmicas que se transformaram no decorrer da licenciatura em pedagogia. De fato, de categorias prévias, próximas do senso comum, essas noções passaram por ressignificações resultantes da formação no ensino superior orientada pelos conhecimentos pedagógicos difundidos na educação universitária.

A partir dessas categorias, inicialmente perguntou-se aos estudantes quais eram as suas concepções sobre criança antes de terem entrado no curso de pedagogia. De acordo com as falas dos estudantes entrevistados, pudemos propor características comuns organizadas em quatro categorias de análise: concepção e visão naturalista; concepção e visão individualizante; concepção e visão educativa; e, concepção e visão fragilista. Essas definições de concepção e visão estão presentes na construção das categorias de análise as quais consideramos representativas do pensamento esquemático dos estudantes 
A compreensão sobre socialização e criança na educação infantil: o que muda com o curso de pedagogia?

sobre as temáticas da pesquisa, tal como pudemos perceber nas respostas, chegando-se às denominações significativas, definidas da seguinte forma:

- (CVN) Naturalista: Concepção/Visão de criança e infância como ser e condição em desenvolvimento, tanto como processo natural ou biológico.

- (CVII) Individualizante: Concepção/Visão de criança e infância como ser social e indivíduo comum, sendo também um grupo particular.

- (CVE) Educativa: Concepção/Visão de criança e infância como ser de aprendizagem e objeto de ensino, mas na perspectiva educacional do adulto.

- (CVF) Fragilista: Concepção/Visão de criança e infância como ser incapaz e frágil ou ser em condição vulnerável, inclusive não dotado de capacidade racionais plenas.

Essas categorias, assim como todas as outras que serão apresentadas, não foram adotadas previamente, mas sim criadas com base em sucessivas leituras reflexivas das transcrições das entrevistas. Etapa seguinte, selecionamos trechos ou fragmentos significativos que associamos às categorias propostas. Como demonstração desse processo de análise, apresentamos no Quadro 1, a seguir, com os códigos e número de menções encontradas, que se acom276 panham de alguns exemplos dos trechos retirados da transcrição das falas dos entrevistados, dentre as que foram identificadas com as quatro categorias apresentadas. 


\section{Quadro 1}

Concepção/Visão sobre a criança antes de entrar no curso de Pedagogia

\section{Trechos ou fragmentos significativos por categorias/\% das menções/ Exemplos}

Naturalista/35\%

- Mais voltada para a parte biológica.

- Ser em processo de crescimento e ser incompleto.

Individualizante/23,5\%

- Tem suas particularidades.

- Indivíduo como qualquer outro.

Educativa/23,5\%

- Aprendi a lidar melhor com elas (crianças).

- Se ensinar muito, a criança não aprende.

Fragilista/ $18 \%$

- Ser que precisa de cuidados.

- Não dotado de capacidades racionais

Como resultado da tabulação das respostas para a questão "Qual a concepção que você tinha de criança antes de entrar no curso de pedagogia?", obteve-se os números relativos a partir do total das respostas. De acordo com as concepções que os entrevistados tinham de criança, antes de entrar no curso de pedagogia, se percebeu que a maior participação era de uma concepção e visão que se denominou de naturalista (35\%), levando em consideração a ideia de que o desenvolvimento da criança ocorreria sobretudo do ponto de vista natural ou biológico. Junto com a concepção chamada de individualizante $(23,5 \%)$, porque se levaria mais em conta a criança como ser social e grupo particular, representou bem mais da metade das expressões que os entrevistados relacionaram com as suas ideias sobre criança. As diferentes concepções de criança, entre o desenvolvimento da natureza e a condição social, parecem corresponder à visão tradicional que é predominante no senso comum da sociedade contemporânea, marcada pelo determinismo, seja biológico seja do meio social. Todavia, também se notou uma visão de respeito à individualidade da criança e à particularidade da infância, ainda que pela 
A compreensão sobre socialização e criança na educação infantil: o que muda com o curso de pedagogia?

falta de definições claras se mantenha a muito antiga imagem da criança como a de uma espécie de miniadulto.

Em outro sentido, a concepção e visão de criança considerada como educativa (23,5\%), com o mesmo peso da categoria "Individualizante", implicaria a atuação transformadora da educação, ainda que dominada pelo mundo adulto, poderia ser vista como indicador da aceitação da possibilidade, pelo ensino e pela aprendizagem das crianças, de futura mudança social e individual. Entretanto, menos de um quarto dos entrevistados declararam terem tido essa concepção prévia da criança como indivíduo capaz. Ao contrário, a concepção denominada de fragilista (18\%) destacaria logicamente uma visão na qual prevaleceria a ideia de incapacidade global atribuída à criança, inclusive destituida de recursos racionais suficientes. Assumindo-se que essa fragilidade ocorreria especialmente na infância, com a consequente necessidade de cuidado extremo com a criança, essa concepção de ser incapaz e dependente limitaria durante a infância as possibilidades da educação baseada na autonomia.

Em seguida, perguntou-se aos estudantes que visão eles passaram a ter de criança e infância após terem entrado no curso de pedagogia. Como 278 resultado da tabulação das respostas para a questão "Que visão passou a ter sobre criança e infância após entrar no curso de Pedagogia?", identificadas e codificadas de acordo com as mesmas categorias definidas anteriormente. $\bigcirc$ conjunto dos trechos ou fragmentos significativos, como expressões chaves dos entrevistados para essa questão, tendo como referência as mesmas categorias identificadas na pergunta anterior, resultou no Quadro 2, a seguir. 


\section{Quadro 2}

\section{Concepção/Visão sobre criança e infância após entrar no curso de pedagogia}

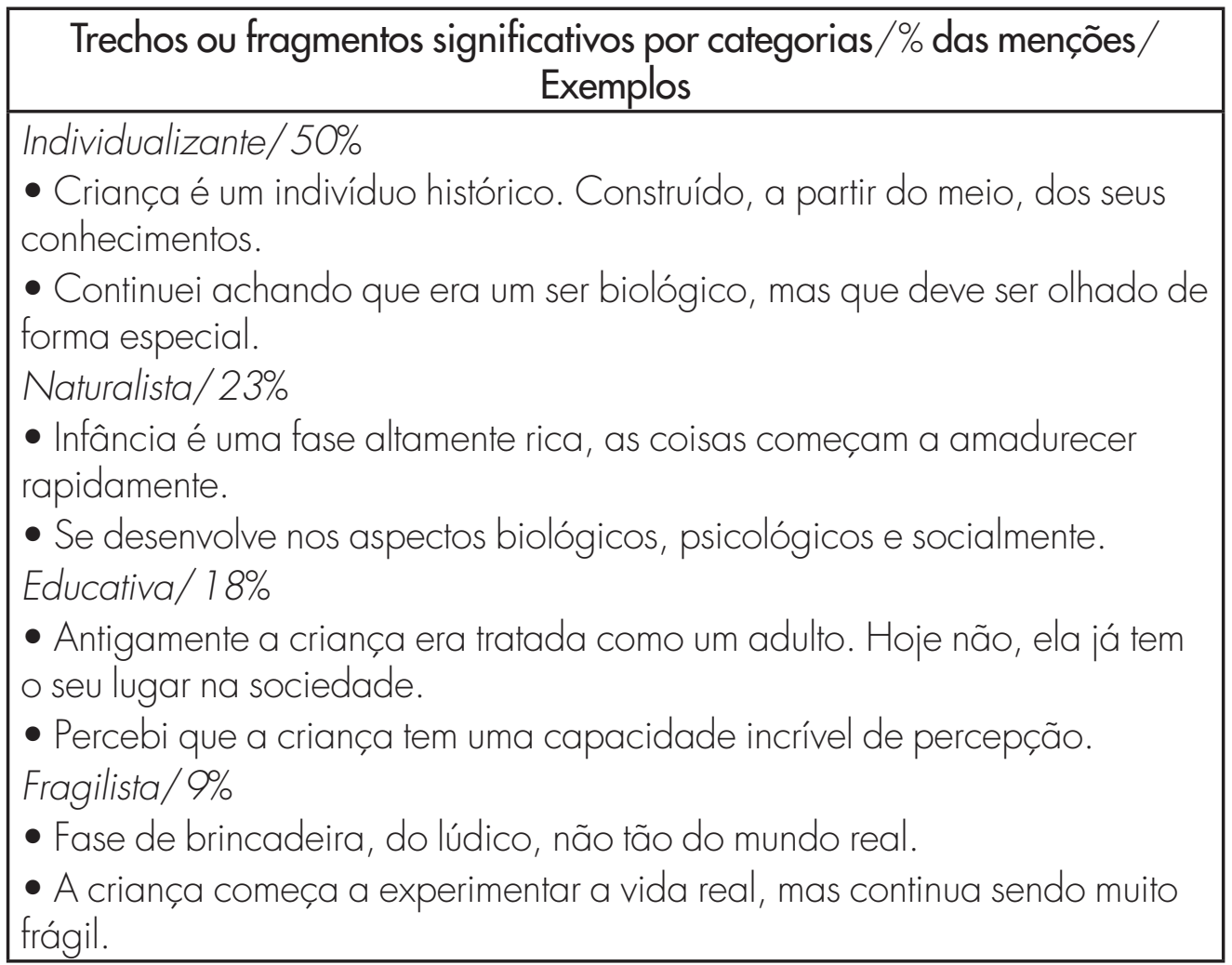

Após ingressar no curso de pedagogia, se comparada com a situação de antes do ingresso no curso, há uma grande diminuição da concepção e visão denominada naturalista (23\%) entre os estudantes entrevistados, provavelmente devido ao contato com as proposições das disciplinas de fundamentos. De fato, as áreas dessas disciplinas trazem a discussão dos conteúdos históricos, filosóficos, sociológico e psicológicos, com os quais se espera que os estudantes consigam relaciona-los nas situações de práticas escolares propostas pelo curso. Nessa lógica, entre os entrevistados essa mudança quando se observa o aumento das expressões identificadas com a concepção e visão denominada de individualizante (50\%). Isso significaria que eles passaram a dar uma maior importância à criança como indivíduo, ou seja, como ser que tem o seu desenvolvimento melhor relacionado à dimensão social e cultural. 
A compreensão sobre socialização e criança na educação infantil: o que muda com o curso de pedagogia?

Contudo, pelas falas dos estudantes ainda se observa que no contexto escolar da infância se mantem uma perspectiva adultocêntrica da socialização da criança.

Compreensivelmente, observou-se que entre os entrevistados, após entrarem no curso de pedagogia, ocorreu uma forte diminuição da visão fragilista $(9 \%)$ da criança e da infância. $\bigcirc$ que corresponderia às discussões mais racionais e científicas da formação superior. Entretanto, as respostas dos estudantes, se comparadas às concepções antes de entrar no curso, mostraram igualmente uma sensível diminuição na visão educativa da criança (18\%). De um lado, no sentido da formação acadêmica dos estudantes, isso poderia ser um indício da persistência de dificuldades teóricas e práticas para se dominar com segurança as bases do ensino e da aprendizagem na educação infantil, no contexto escolar. Por outro lado, seria razoável essa relativa redução nas possibilidades da concepção educativa da criança, devido ao reconhecimento da complexidade e do teor crítico das ações e propostas pedagógicas para a educação infantil, sobretudo como se apresentam na formação superior. Com os percentuais das duas questões apresentadas, relacionados às categorias de análise definidas, elaborou-se o gráfico 1, a seguir.

\section{Gráfico 1}

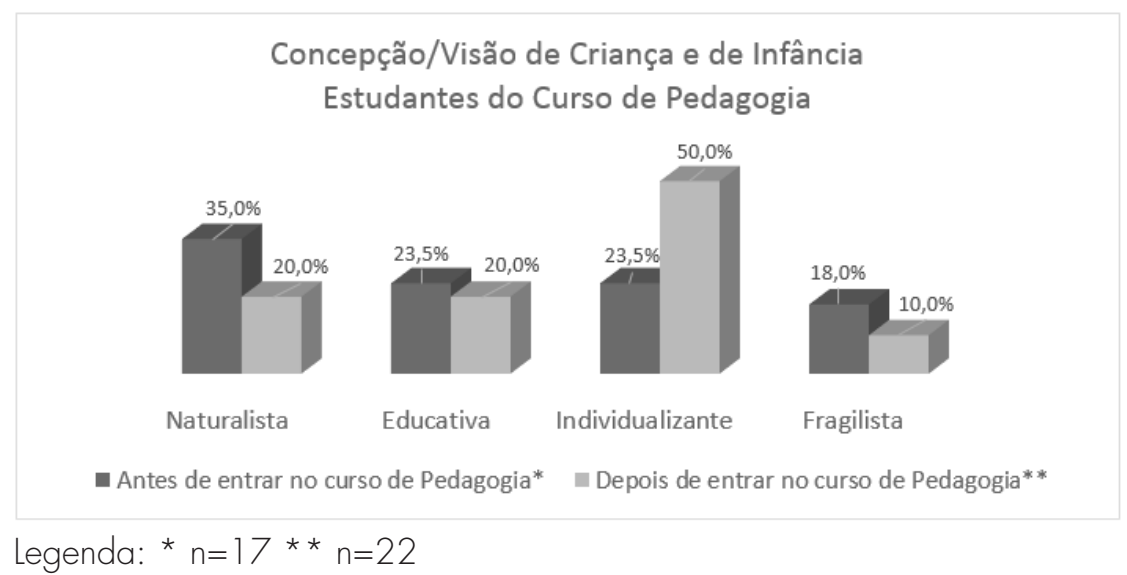

Na sequência da análise, sempre a partir das respostas dos estudantes, criou-se caracterizações para que fosse possivel identificar e classificar as formas de representação sobre educação infantil e formação da criança, as quais poderiam ser apresentadas nas seguintes categorias: 
- (IFC) Instituição de formação curricular: destaca-se a importância da escola na educação infantil como instituição de formação curricular da criança.

- (MFS) Meio de formação social: valoriza-se a importância da escola de educação infantil como meio para a formação social da criança.

- (LFP) Lugar de formação da personalidade: ressalta-se a importância da escola de educação infantil como lugar para a formação da personalidade da criança.

Nesse sentido, perguntou-se diretamente aos entrevistados qual seria a importância da educação infantil para a formação da criança, com o objetivo de se detectar as relações entre educação infantil e criança que estariam presentes entre os estudantes de pedagogia. $\bigcirc$ conjunto dos trechos ou fragmentos significativos, como expressões chaves dos entrevistados para essa, questão resultou no Quadro 3, a seguir:

\section{Quadro 3}

Importância da educação infantil para a formação da criança

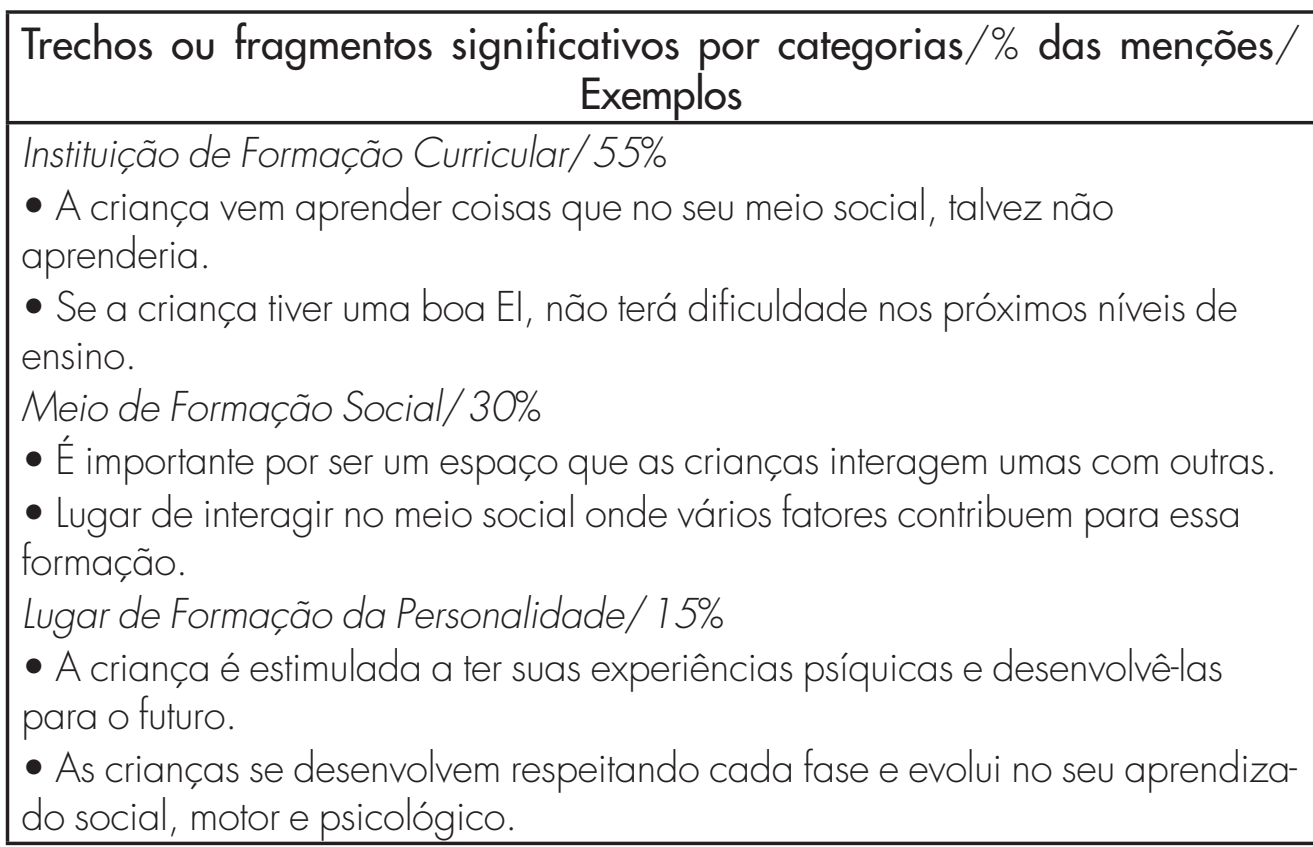

Considerando-se as falas dos entrevistados, tomadas como referências para a identificação dessas três categorias, chegou-se aos resultados 
A compreensão sobre socialização e criança na educação infantil: o que muda com o curso de pedagogia?

relativos, mostrados em percentual, a partir do número absoluto dos trechos ou fragmentos significativos encontrados nas expressões colhidas junto aos entrevistados. Outra maneira de mostrar as formas de representação da importância da escola de Educação Infantil para a formação da criança, a partir das palavras dos estudantes de pedagogia, é através do gráfico 2, a seguir. Sobre esse assunto, o gráfico mostra a predominância da formação curricular, tal como acontece tradicionalmente na escola da educação infantil. Também se pode perceber uma menor importância associada à escola de Educação Infantil naquilo que se possa relacionar com a formação social e com a formação da personalidade da criança.

\section{Gráfico 2}

\section{Importância da EI na formação da criança}

FORMAÇÃO DA

PERSONALIDADE

$15 \%$

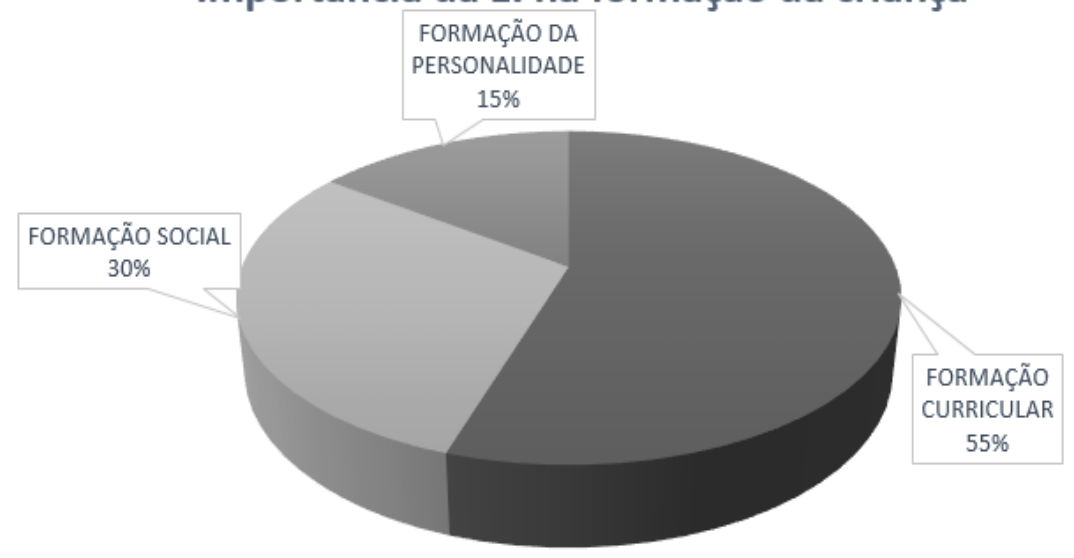

$n=20$

Destaca-se claramente que, para a imensa maioria dos estudantes, a importância da educação infantil para a formação da criança está relacionada à tradicional perspectiva da escola como a instituição de formação curricular (55\%). Em muito menor número, encontram-se os entrevistados que valorizavam a escola da educação infantil como meio de formação social (30\%). Proporcionalmente apenas um e meio em cada dez estudantes ressaltaram a importância da escola como lugar de formação da personalidade (15\%). Embora a ideia de formação integral, integrando as dimensões do cognitivo, do social e do pessoal, seja bastante difundida no pensamento educacional (base da formação em pedagogia), o que se sobressai é a imposição da 
cultura do currículo escolar, definido especialmente pela abordagem pedagógica e pela organização didática tradicionais.

Aparentemente, entre os estudantes entrevistados há uma contradição de noções, com o nítido domínio da visão da formação curricular como o mais importante da Educação Infantil para a formação da criança. Enquanto que os números relativos são bem menores para a concepção/visão educativa de criança e de infância. E isso, mesmo após o ingresso no curso de pedagogia. Todavia, esse paradoxo pode ser entendido como a expressão do indiscutível papel social da educação formal e até da exaltação da importância do espaço escolar para a formação da criança. Ao mesmo tempo em que se admite os limites pedagógicos da visão educativa, com caráter coletivista, justamente na escola da Educação Infantil, assimilando-se, em contrapartida, o reconhecimento da concepção e da visão individualizante de criança no contexto escolar, como indivíduo e ser social com seu próprio caminho.

\section{Socialização de crianças, papel da professora e ação da escola na educação infantil}

Quanto às questões voltadas para o foco da formação acadêmica e profissional, foram colocadas perguntas direcionadas para o que se espera como conjunto de conhecimentos e competências de uma professora trabaIhando na educação infantil, tal como prevê o currículo e a habilitação do curso de pedagogia para esse campo de trabalho. Sobre isso, procuramos as compreensões de algumas categorias consideradas como parte já dominada pelos estudantes avançados, ou veteranos, de acordo com o currículo e as qualificações profissionais da licenciatura em pedagogia. Sobre isso, buscamos conhecer os sentidos atribuídos pelos estudantes à socialização de crianças, naqueles aspectos ligados à prática da professora e à própria organização da escola,

Supõe-se que com a bagagem de conhecimentos adquiridos no decorrer do ensino superior, como capital cultural acadêmico específico resultante da experiência vivida no estágio supervisionado, os estudantes entrevistados pudessem focalizar melhor conteúdos relacionados à Educação Infantil, assim como relatar fenômenos de tipo sociológico na prática de educadores de crianças. Assim, com a ideia de que muitos pressupostos curriculares da pedagogia 
A compreensão sobre socialização e criança na educação infantil: o que muda com o curso de pedagogia?

já estivessem assimilados, assumimos que as respostas tenham refletido o pensamento corrente entre os estudantes, ou seja, pressupostos educacionais pertinentes e em conformidade à média dos estudantes de pedagogia. De fato, espera-se dos estudantes veteranos que eles já tenham incorporado aspectos da futura vida profissional, tais como socialização escolar, papel do professor, gestão escolar e de classe. Assim, como uma descrição geral das dimensões sociais no funcionamento normal de uma escola, esses problemas educacionais envolvem especialmente a experiência cotidiana com a didática e com as atividades próprias da Educação Infantil e a interação individual e coletiva com crianças em sala de aula.

Como uma questão de inspiração sociológica, imaginando que o reconhecimento da dimensão social possa melhorar um diagnóstico pedagógico do grupo da sala de aula, colocou-se para os entrevistados a pergunta: "Como você percebe a socialização das crianças na Educação Infantil?". Após a leitura das respostas, foi possível identificar as partes nas quais percebemos indícios suficientes para definir as categorias de análise sobre processo de socialização nos relatos dos estudantes. Assim, a partir de trechos e fragmentos das falas, propomos as definições para as categorias de resposta, colocadas 284 adiante no Quadro 4:

- Visão coletivista: relaciona a socialização das crianças com aspectos sociais coletivos, reforçados pelas regras institucionais da escola e pela convivência com outras crianças, ligados à interação entre pares e às relações do grupo infantil com os adultos;

- Visão subjetivista: associa a socialização com aspectos subjetivos das crianças, como sujeitos particulares identificados com o desenvolvido psicológico individual próprio das fases infância, reconhecidos ou estimulados pela escola;

- Visão interacionista: assume a socialização das crianças como o resultado combinado, no decorrer da vida escolar, de uma interação entre a experiência social coletiva, com outras crianças e adultos, e o comportamento psicológico particular da própria criança. 


\section{Quadro 4}

Percepção da socialização das crianças na Educação Infantil

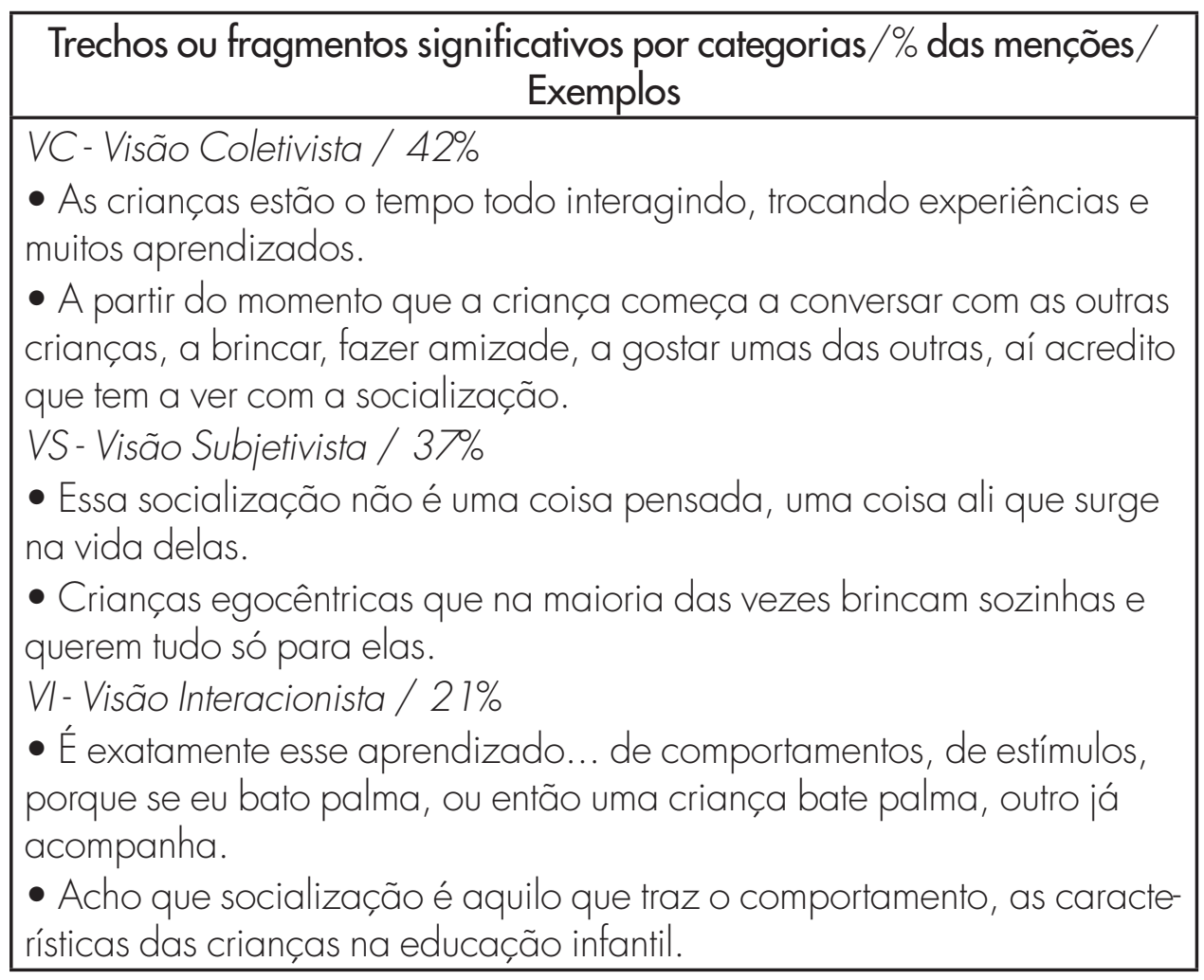

Como se pode ver no Gráfico 3, a seguir, se destacam os números relativos próximos da Visão Coletivista (42\%) e da Visão Subjetivista (37\%), diante de uma percepção menor da Visão Interacionista (21\%). É como se houvesse uma alternância ou uma divisão de percepção entre o social e o individual, entre o coletivo e subjetivo. Talvez, essas dimensões educacionais, intrincadas na realidade, pudessem ser vistas como imaginárias instâncias separadas, sendo possível definir isso no tempo didático e na organização do espaço da sala de aula, assim como na própria experiência escolar da socialização das crianças. 
A compreensão sobre socialização e criança na educação infantil: o que muda com o curso de pedagogia?

\section{Gráfico 3}

Como o estudante de Pedagogia percebe a socialização das crianças na EI

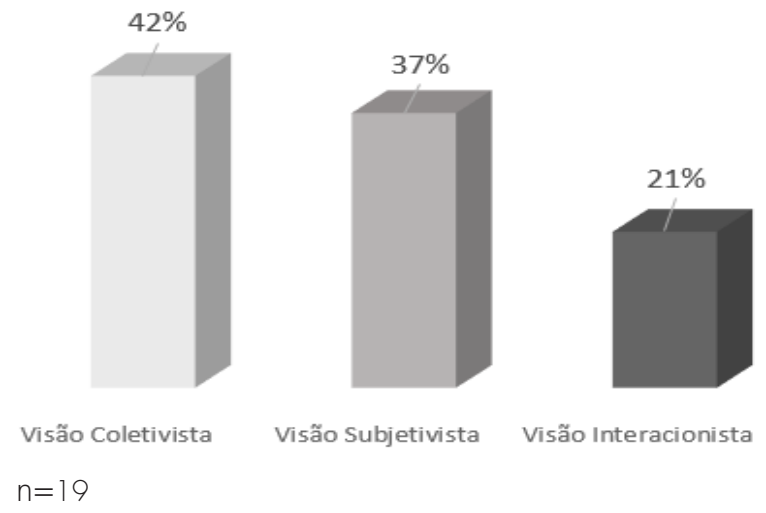

Entretanto, parece ocorrer uma sensibilidade menor à percepção integradora entre essas instâncias educacionais, que poderia representar a perspectiva interacionista significando a dialética entre as dimensões do cole286 tivo e do subjetivo. Muitos pensadores clássicos da educação (Piaget, Vygotsky, Dewey, Freire) justamente inspiraram abordagens interacionistas como forma de superar a fragmentação entre o social e o psicológico. Entretanto, os próprios estudantes ainda mantêm essa dicotomia nas suas percepções sobre o fenômeno da socialização infantil.

Com isso em mente, seria preciso que se continuasse a avançar sobre um melhor entendimento do papel da professora e da ação da escola sobre a socialização da criança. Foi com esse intuito que se colocou a seguinte questão para os entrevistados: "Qual o papel da professora e da escola no processo de socialização das crianças?" Então, a partir das respostas construímos as duas seguintes categorias de análise:

- Papel de direcionamento e intervenção - esse papel foi definido pela condição e pela situação nas quais se destacava especialmente a iniciativa da professora para direcionar a socialização da criança na escola, com a tendência pedagógica de interferir nesse processo nas atividades de sala de aula e no próprio grupo das crianças.

- Papel de mediadora e facilitação: esse papel foi definido pela condição e pela situação nas quais se observou frequentemente a mediação e a facilitação 
entre adulto-criança, desempenhado pela prática da professora na socialização das crianças no decorrer da rotina da sala de aula.

Buscando essas categorias se organizou o Quadro 5, a seguir, com as respostas dos entrevistados mostrando como eles observaram, em suas salas do estágio supervisionado, o papel da professora na socialização as crianças. Como se viu, em um total de vinte dois menções selecionadas, em um dos dois percentuais, se comparando um ao outro, se encontrou do que o dobro de menções atribuídas ao papel de direcionamento e intervenção (68\%). Enquanto as menções associadas ao papel de mediação e de facilitação corresponderam apenas a cerca de um terço do total (32\%).

\section{Quadro 5}

\section{O papel da professora e da escola no processo de socialização das crianças}

Trechos ou fragmentos significativos por categorias/\% das menções/ Exemplos

Papel de Direcionamento e Intervenção / 68\%

- Na El, o brincar é muito forte e algumas crianças se recusam a se socializar.

- Tem um papel fundamental através das atividades realizadas em sala, ou nos momentos de as crianças trocarem brinquedos e conversa.

Papel de Mediação e Facilitação / 32\%

- A professora é uma facilitadora e mediadora.

- Reconhecer que cada criança tem seu tempo e aprende de uma maneira diferente.

Expressando os resultados através do Gráfico 4, a seguir (Papel da professora na socialização infantil), fica mais evidente ainda que em sua imensa maioria os estudantes entrevistados viram o papel da professora como o de direcionadora e de interventora no processo de socialização das crianças, ao invés de considerarem o papel de mediadora e de facilitação. Com esses resultados se pode depreender que, diante da socialização das crianças, os estudantes de pedagogia assumem muito mais claramente a prevalência da ação pedagógica unilateral da professora. Enquanto, por outro lado, eles imaginam um espaço bem menor para a mediação adulto-crianças como parte 
A compreensão sobre socialização e criança na educação infantil: o que muda com o curso de pedagogia?

do processo socializador infantil na escola. Ainda que de forma atenuada e justificada com argumentos pedagógicos, como aqueles que orientam os objetivos de ensino-aprendizagem dos planejamentos de aulas, permanece a ideia da autoridade centralizadora do professor. No cotidiano escolar da Educação Infantil, muitas vezes isso se converte em um campo explícito ou velado para o autoritarismo "educativo" do adulto sobre os interesses das crianças.

\section{Gráfico 4}

\section{Papel da professora na socialização infantil}

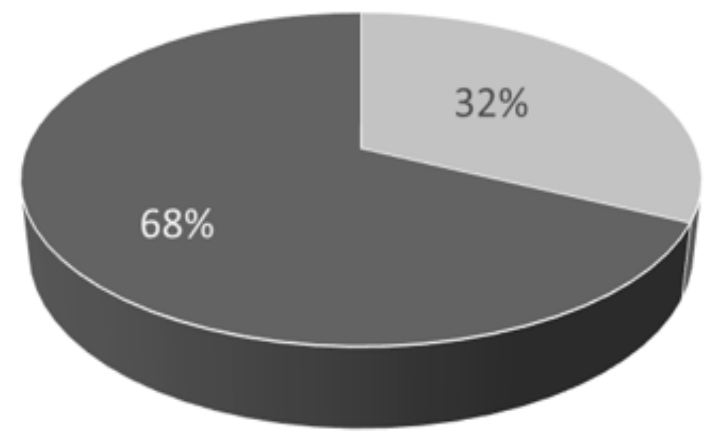

= Mediadora (Facilitação) - Direcionadora (Intervenção)

$n=22$

Outro aspecto na imposição da cultura do mundo adulto sobre o mundo das crianças na Educação Infantil é a importância atribuída pelos professores às dimensões organizacionais do estabelecimento escolar. Nesse sentido, colocamos à seguinte questão para os entrevistados: "Qual a importância do estabelecimento escolar para a socialização das crianças?". A partir das opiniões expressas pelos estudantes de pedagogia, como se pode ver no Quadro 6, puderam ser organizados as seguintes categorias relacionadas com a atribuição de importância das estruturas da escola que mais influenciam na socialização das crianças:

- Gestão escolar e pessoal de apoio (direção, gestores e funcionários);

- Infraestrutura física e materiais (instalações, recursos, mobília, etc.);

- Relações sociais e integração no ambiente físico lespaços, alunos, professores); 
- Valor cultural da instituição escolar (imagem pública da escola como instituição).

\section{Quadro 6}

A importância do estabelecimento escolar para a socialização das crianças

\section{Trechos ou fragmentos significativos por categorias/\% das menções/ Exemplos}

Gestão escolar e pessoal de apoio/43\%

- $\bigcirc$ pessoal de apoio deve estar integrado na escola e participar de todas as discussões, saber os projetos da escola, isso é fundamental.

- Os gestores devem acompanhar os projetos das salas para atrelar a um projeto mais amplo, o da escola.

Estrutura física e materiais/32\%

- A criança está comendo, ela tá socializando com os amigos, ela também tá se desenvolvendo... não falo só da alimentação, mas de brinquedo, livro.

- Adaptação da mobília facilita a criança a fazer o que ela observa o adulto fazer.

Relações sociais e integração no ambiente físico/ $14 \%$

- Todos os espaços da escola são para promover as relações das crianças com a equipe da escola.

- Quando as crianças interagem com as diversas pessoas em diferentes funções ela compreende e compara o papel de cada um.

Valor cultural da instituição escolar/ 1 \%

- Como a criança não está na escola, não está socializada com outras crianças, aí ela não vai saber lidar com as diferenças.

- Ajuda a criança a conviver com as diferenças e se inserir na cultura.

Como se pode perceber no Gráfico 5, os estudantes de pedagogia quando pensaram na socialização das crianças nitidamente atribuíram uma maior importância à dimensão da gestão da escola e do pessoal de apoio (43\%). Os aspectos da infraestrutura física e dos materiais também foram mencionados como muito relevantes (32\%). Entretanto, às relações sociais nos espaços do estabelecimento, as quais são certamente estruturam o funcionamento da escola, foram menos consideradas pelos entrevistados (14\%). 
A compreensão sobre socialização e criança na educação infantil: o que muda com o curso de pedagogia?

Igualmente, foi bem menos designado o valor cultural e institucional da escola (11\%), na sua relação com a socialização infantil. De fato, em termos de importância para a socialização infantil, se pode observar que três quartos da importância foi atribuída à conjugação da gestão da escola com as condições de infraestrutura e de materiais. Em outras palavras, considerando os fatores de influência na socialização infantil, aparentemente os estudantes de pedagogia não compreenderiam muito bem a dimensão do convívio social nos ambientes físicos do estabelecimento escolar, assim como o valor cultural e simbólico da escola como instituição.

\section{Gráfico 5}

\section{Importância do Estabelecimento Escolar para a Socialização das Crianças}

Gestão escolar e pessoal de apoio

Estrutura física e materiais

290
Relações sociais-ambiente físico

Valor cultural da instituição escola

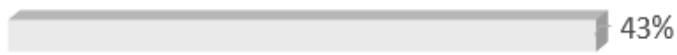

$32 \%$

$n=28$

Em outro sentido, mais especificamente de caráter sociológico sobre a atuação das crianças, em relação à própria socialização escolar e às atividades cotidianas, questionou-se os entrevistados com a seguinte pergunta: "Como você considera a participação das próprias crianças no processo de socialização?". Os estudantes destacaram que no processo de socialização escolar há muito mais interação com pares, se comparada com uma interação igual com pares e adultos, ou com interação mais com adultos. Isso significaria que os estudantes entrevistados consideraram que a socialização das crianças no ambiente escolar ocorre muito mais pelas interações entre elas próprias, com uma participação menor da interação com os adultos. 


\section{Quadro 7}

Como considera a participação das crianças no processo de socialização?

\section{Trechos ou fragmentos significativos por categorias/\% das menções/ Exemplos}

Mais interação com pares/54\%

- Elas (as crianças) criam ou deixam na escola, mas elas também produzem cultura.

- Estão socializando entre si, algumas (crianças) vão praticar, ou pular ou correr, então isso tende a ser uma forma de socialização.

Interação igual com pares e adultos/25\%

- Elas são mais comunicativas e se envolvem mais nas relações humanas.

- A partir do momento em que a criança participa, ela já está em um momento de socialização.

Mais interação com adultos/21\%

- As crianças necessitam muito da intervenção do adulto para gradativamente conseguir se socializar.

- $\bigcirc$ adulto é que faz interrupções com julgamentos morais e comportamentais.

Noutra forma de visualização desses resultados, pode-se observar no Gráfico 6, os entrevistados perceberam que há mais interação com pares (54\%), se comparado com igual interação com pares e adultos (25\%), ou mais interação com adultos (21\%). Aparentemente, há uma contradição dessa percepção entre os futuros professores da Educação Infantil e a atuação esperada dos professores na socialização das crianças. Isso poderia ser interpretado como uma visão educacional, mas paradoxal, sobre a socialização escolar: os objetivos pedagógicos de socialização dos adultos seriam distintos do sentido espontâneo da socialização vivenciado pelas próprias crianças. das crianças, Como efeito da auto-organização das crianças, seria como se essa socialização espontânea fosse algo à parte e sem relevância para a socialização escolar visada pela ação pedagógica dos adultos. Certamente essa é a contradição que se destaca quando vemos a subestimação da atuação das crianças, como atores sociais efetivos, mesmo na sua peculiaridade etária 
A compreensão sobre socialização e criança na educação infantil: o que muda com o curso de pedagogia?

e escolar. Apesar dessa questão, a experiência social com seus pares é vista como o mais marcante na concepção e visão dos entrevistados.

\section{Gráfico 6}

\section{Percepção da interação das crianças no processo de socialização na EI}

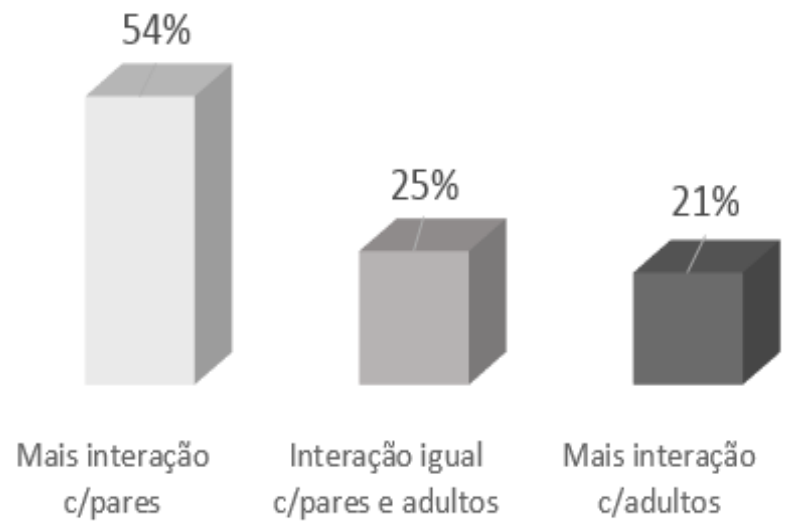
$n=24$

Também se procurou saber sobre a percepção dos estudantes de pedagogia a respeito da consideração, por parte da professora observada no estágio de $\mathrm{El}$, no encaminhamento pedagógico das atividades e da rotina de aula. A questão formulada a eles foi: "A partir da sua experiência no estágio supervisionado na El, como você percebe o olhar da professora diante da atuação da criança nas atividades e na própria organização da rotina?". Com as falas dos entrevistados, como se vê no Quadro 8, identificou-se as seguintes categorias sobre a percepção do olhar das professoras:

- Controle do grupo (olhar de disciplinamento do grupo infantil);

- Condução das atividades (olhar de condução pedagógica das atividades);

- Aceitação da autonomia (Olhar de aceitação diante da autonomia da criança).

Como se pode ver, com o mesmo percentual de menções dos entrevistados $(40 \%)$, predominaram os olhares de controle do grupo e de condução 
das atividades, enquanto a aceitação da autonomia da criança (20\%) foi muito menos observada.

\section{Quadro 8}

Olhar da professora diante da atuação da criança

\section{Trechos ou fragmentos significativos por categorias/\% das menções/ Exemplos}

Controle do grupo (disciplinamento do grupo)/40\%

- As crianças não participavam da elaboração da rotina, tudo feito pela professora que "as vezes" acatava o que os alunos diziam.

- Faltou muito a iniciativa de permitir que as crianças elaborassem suas próprias atividades.

Condução das atividades (condução pedagógica das atividades)/40\%

- No momento da roda, todos participam construindo a rotina, a partir das perguntas da professora, tipo: o que vamos fazer hoje?

- Desenvolve a autonomia da criança, mas de acordo com a rotina da escola e com os objetivos pedagógicos e regras de comportamento. Aceitação da autonomia (aceitação da autonomia da criança)/20\%

- Algumas vezes a professora realmente pedia a opinião das crianças, elas davam, e a professora às vezes até acatava, né!

- As crianças estão adaptadas à rotina da sala, têm espaço para ir dizendo na sequência os acontecimentos.

Colocando-se os trechos dessa mesma questão em forma gráfica (Gráfico 7), a soma dos resultados relativos dos olhares de controle do grupo e de condução das atividades corresponde à $80 \%$ das menções. Isso mostra a nítida predominância dessas atitudes das professoras diante da condução das crianças em sala de aula. Efetivamente, a percepção de um olhar de aceitação da autonomia da criança, nas atividades e na organização da rotina correspondeu somente a $20 \%$ das respostas dos entrevistados. Esses quantitativos, por parte da professora, mostram que a consideração da autonomia infantil no ambiente escolar é marginal, devido à permanência do tradicional peso educacional atribuído ao poder do adulto em detrimento das formas de ałuação das crianças. 
A compreensão sobre socialização e criança na educação infantil: o que muda com o curso de pedagogia?

\section{Gráfico 7}

\section{Olhar da professora da El diante da atuação da criança}

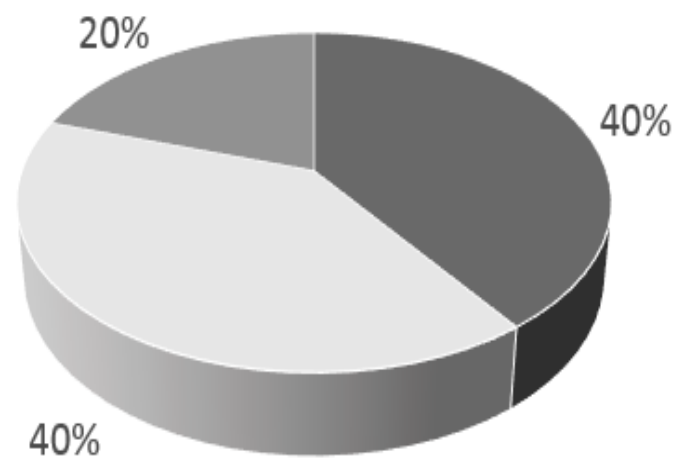

$$
\begin{aligned}
& \text { - Controle do Grupo - Condução das Atividades Aceitação da Autonomia } \\
& \text { n=30 }
\end{aligned}
$$

294 Contudo, mesmo percebendo essa desconsideração da autonomia das crianças na Educação Infantil, que é uma das bases críticas das análises da sociologia da infância, os estudantes entrevistados não revelaram, a partir de sua formação para a docência, ter tido um conhecimento profundo sobre a socialização infantil. É o que se depreendeu quando se fez aos entrevistados a pergunta: "Como você compreendeu o entendimento dos seus professores do curso de pedagogia sobre socialização das crianças na Educação Infantil?". Como se observar no Quadro 9, a seguir, na maior parte dos casos, os estudantes relataram terem pouco conhecimento sobre a socialização infantil, ainda que imaginassem que fosse algo importância. 


\section{Quadro 9}

Entendimento dos professores sobre socialização na Educação Infantil

\begin{tabular}{|c|}
\hline $\begin{array}{l}\text { Trechos ou fragmentos significativos por categorias/\% das menções/ } \\
\text { Exemplos }\end{array}$ \\
\hline $\begin{array}{l}\text { Pouco trataram do papel da socialização/58\% } \\
\text { - Poucos professores falaram de socialização na El. } \\
\text { - O que eu aprendi mesmo da Educação Infantil, foi no meu estágio. } \\
\text { Destacaram a importância da socialização/ } 3 \text { 1\% } \\
\text { - Todos os professores enfatizam a socialização das crianças, que a gente } \\
\text { tem que incentivar e participar junto com elas. } \\
\text { - Se fala sobre socialização nas disciplinas da Educação Infantil, } \\
\text { Alfabetização e Letramento e Ciências. } \\
\text { Relacionaram aprendizagem e socialização/ } 1 \text { 1\% } \\
\text { - Os professores buscam fazer atividades ou planejar de forma que os } \\
\text { alunos trabalhem no coletivo como se fossem conceitos atitudinais. } \\
\text { - Fazem com que os alunos interajam não só com a turma, mas também } \\
\text { com o conteúdo. }\end{array}$ \\
\hline
\end{tabular}

Colocando-se essas informações como se pode ver no Gráfico 8, mostra-se que a maioria dos estudantes entrevistados, a partir das disciplinas de sua formação em pedagogia, ficaram com a impressão de que os professores pouco trataram sobre o papel da socialização na El (58\%). Enquanto uma minoria mencionou que todos os docentes destacaram a importância da socialização infantil (31\%). Entretanto, apenas um pequeno número de estudantes relatou que alguns dos seus professores estabeleciam uma relação entre aprendizagem e socialização na Educação Infantil ( 1 1\%). 
A compreensão sobre socialização e criança na educação infantil: o que muda com o curso de pedagogia?

\section{Gráfico 8}

\section{Entendimento dos professores de pedagogia sobre socialização das crianças na El}

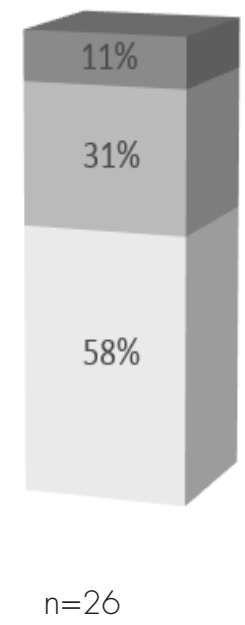

- Alguns relacionaram aprendizagem e socialização

- Todos destacaram a importância da socialização

Poucos trataram do papel da socialização

Considerando-se a docência na Educação Infantil como uma das habilitações conferidas pelo curso de pedagogia, não deixa de ser um resultado surpreendente os estudantes não terem razoável conhecimento da importância da socialização escolar, mesmo tendo cursado disciplinas de fundamentos sociológicos e psicológicos. É razoável pensar esses relatos como resultado de um esperado esquecimento dos conteúdos teóricos apresentados aos estudantes três ou quatro anos antes. Mais tarde, para frustração dos seus antigos professores, no período dos estágios supervisionados os supostos conhecimentos adquiridos pelos estudantes no passado das disciplinas de fundamentos, se transformam em um incerto e confuso sentimento de falha pedagógica. Todavia, também é provável que as falas dos estudantes realmente mostrem a ausência de ensino de conteúdos sobre socialização infantil e escolar no decorrer da sua formação acadêmica e preparação profissional. 


\section{Considerações finais}

Aparentemente, encontramos algumas das razões para o dilema dos estudantes de pedagogia que se preparavam para uma futura atuação na Educação Infantil: eles perceberam que deixavam para trás as suas concepções ingênuas de crianças de antes de entrar no curso, mas tiveram dificuldades em aprender as bases para uma visão mais educativa e individualizante de criança, informada pela psicologia e pela sociologia. Além disso, ainda careciam de profundidade e clareza para uma abordagem pedagógica das crianças e da infância. Ademais, a despeito da valorização do indivíduo criança, haveria mesmo uma contradição de valores quando se observa que é dada menor importância para a formação social e da personalidade. E isso logicamente entra em choque com a proposição de que a escola na infância deve considerar a criança como ser integral. Em outras palavras, a organização escolar na El ainda precisaria transpor os limites de se concentrar demasiadamente nos seus objetivos curriculares e cognitivos, sem reconhecer com a mesma importância a escola como espaço de liberdade para a socialização das crianças.

De acordo com as falas dos entrevistados, considerados como representativos dos estudantes avançados do curso de pedagogia, se pode identificar as seguintes características predominantes: a) têm uma visão coletivista da socialização infantil, assumindo como normal que os docentes tenham o papel de direcionamento ou de intervenção pedagógica, sem contar com a atvação as crianças; b) dão mais importância na socialização escolar das crianças para as suas relações de respeito à hierarquia da gestão da escola; c) observam que no ambiente escolar há muito mais interação entre as próprias crianças, em detrimento de momentos de diálogo com os adultos; d) avaliaram que as professoras observadas tinham mais o olhar de controle social e de condução pedagógica sobre as crianças, incluindo pouco a expressão dos interesses do grupo infantil; el assumiram que eles próprios tinham poucos conhecimentos sobre a socialização da criança, mesmo reconhecendo o seu valor para a melhoria da prática docente na Educação Infantil.

De fato, percebeu-se que persistem as orientações pelas perspectivas reducionistas sobre a infância e a criança, as quais se baseiam em argumentos do senso comum sobre a biologia e a psicologia, especialmente nos aspectos 
A compreensão sobre socialização e criança na educação infantil: o que muda com o curso de pedagogia?

da disciplina do grupo e na regulação de atitudes individuais. Ademais, nas suas falas os estudantes de pedagogia reconheceram algumas insuficiências, particularmente nos fundamentos destacados pela sociologia da infância, os quais poderiam contribuir em suas práticas pedagógicas na Educação Infantil. Contudo, também ficou evidenciado que, mesmo tardiamente, o percurso no curso de pedagogia permitiu para esses estudantes a transformação de suas concepções e visões iniciais de infância, especialmente após a experiência de estágio supervisionado na Educação Infantil.

Em conclusão, nossa pesquisa fortaleceu o argumento de que a sociologia da infância traria muitas contribuições para o rompimento da concepção escolar tradicional, porque se continua vendo a criança como dependente, dominada, incapaz, e ser em devir. Ao contrário disso, um olhar sociológico sobre a infância ampliaria o esclarecimento sobre novas possibilidades para ver a criança como sujeito que possui um subestimado valor social, no presente e não como promessa para o futuro. A sociologia da infância propõe justamente isso: uma abordagem crítica sobre visões e experiências sociais que tirem a criança e a infância da sua relativa marginalização no mundo contemporâneo. Talvez, isso poderia abrir uma outra perspectiva no currículo, na formação e nas práticas docentes, trazendo uma outra compreensão do ser criança, na sociedade e na escola.

\section{Referências}

BRASIL. Diretrizes curriculares nacionais para a educação infantil. Brasilia: Ministério da Educação/Secretaria de Educação Básica, 2010.

CORSARO, William Arnold. Sociologia da infância. Porto Alegre: Artmed, 2011.

GIBBS, Graham. Análise de dados qualitativos. Porto Alegre: Artmed, 2009.

LEVINDO, Diniz de Carvalho. Educação integral e institucionalização da infância: o que as crianças dizem da/na escola. Cadernos de Pesquisa em Educação, Vitória, v. 19, n. 42, p. 45-68, jul./dez. 2015.

MARCHI, Rita de Cássia. $\bigcirc$ "ofício de aluno" e o "ofício de criança": articulações entre a sociologia da educação e a sociologia da infância. Revista Portuguesa de Educação, Braga, v. 23, n. 1, p. 183-202, jan./jun. 2010. 
PINTO, Manuel; SARMENTO, Manuel Jacinto. As crianças e a infância: definindo conceitos, delimitando o campo. In: PINTO, Manuel; SARMENTO, Manuel Jacinto. (Org.). As crianças: contextos e identidades. Braga: Central de Estudos da Criança/Universidade do Minho, 1997.

PLAISANCE, Eric. Uma leitura sociológica da educação: visão de Eric Plaisance. Revista Educação em Questão, Natal, v. 7, n. 1/2, p. 135-148, jan./dez. 1997. (Entrevista). Disponível em: https://periodicos.ufrn.br/educacaoemquestao/article/view/10241. Acesso em: 6 nov. 2018.

POWNEY, Janet; WATTS, Mike. Interviewing in educational research. London: Routledge \& Kegan Paul, 1987.

QVORTRUP, Jens. A infância enquanto categoria estrutural. Educação e Pesquisa, São Paulo, v. 36, n. 2, p. 631-64, maio/ago. 2010.

ROSA, Maria Virgínia de Figueiredo Pereira do Couto; ARNOLDI, Marlene Aparecida Gonzales Colombro. A entrevista na pesquisa qualitativa: mecanismo para validação dos resultados. Belo Horizonte: Autêntica, 2006.

SARMENTO, Manuel Jacinto. Infância contemporânea e educação infantil: uma perspectiva a partir dos direitos das crianças. In: SALMAZE, Maria Aparecida; ALMEIDA, Ordália Alves.

Primeira infância no século XXI: direito das crianças de viver, brincar, explorar e conhecer o mundo. Campo Grande: Oeste, 2013.

SIQUEIRA, Romilson Martins. Por uma sociologia da infância crítica no campo dos estudos da infância e da criança. Educativa, Goiânia, v. 16, p. 177-200, jul./dez. 2013.

SIROTA, Régina. Emergência de uma sociologia da infância: evolução do objeto e do olhar. Caderno de Pesquisa, São Paulo, n. 112, p. 7-31, mar. 2001.

Prof. Dr. Adir Luiz Ferreira Universidade Federal do Rio Grande do Norte Departamento de Fundamentos e Políticas da Educação Programa de Pós-Graduação em Educação Coordenador do Grupo de Pesquisa: ECOS-Escola Contemporânea e Olhar Sociológico | CNPq E-mail: adirlfer@gmail.com 
Artigo

A compreensão sobre socialização e criança na educação infantil: o que muda com o curso de pedagogia?

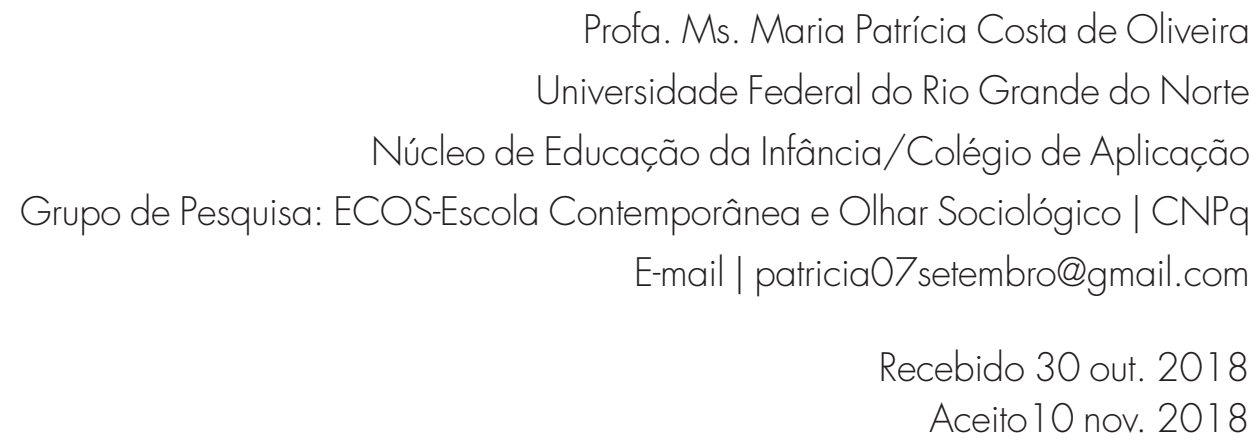

